Article

\title{
Why Enrol in a Lifelong Learning Programme? A Comparative Study of Austrian and Spanish Young Adults
}

\author{
Domingo Barroso-Hurtado ${ }^{1}$ and Ralph Chan ${ }^{2, *}$ \\ ${ }^{1}$ Department of Pedagogy, University of Granada, 18071 Granada, Spain; E-Mail: dobarroso@ugr.es \\ 2 Department of Sociology, University of Vienna, 1090 Vienna, Austria; E-Mail: ralph.chan@univie.ac.at \\ * Corresponding author
}

Submitted: 15 March 2019 | Accepted: 8 July 2019 | Published: 5 September 2019

\begin{abstract}
Lifelong learning (LLL) programmes can be perceived as a means of governing youth transitions. Young adults can use such programmes to try to overcome different constraints in their life course. This article explores the decisions of young adults in Vienna (Austria) and Malaga (Spain) who are participating in different LLL programmes that seek to address their transition from unemployment to employment. In order to understand these decisions, we want to explore: (1) how the young adult's experiences influenced their decision to engage with an LLL programme, (2) what role these programmes played in their biographies and ( 3 ) how young adults imagine their future. We use two theoretical lenses to explore these questions: bounded agency and projectivity. A comparative study of these two regions provides insight into how different contextual conditions influence young adults' decisions. We perform three different analyses: of the young people's past trajectories and transitions, of their imagined futures, and of their decision to enrol in the programme. Exploring young people's subjective accounts of their pasts and their imagined futures helps to improve our understanding of the role young people believe these programmes play in their lives, why they have decided to enrol in them, and how they use and interpret these pathways through, and in the framework of, different contextual conditions.
\end{abstract}

\section{Keywords}

education; employability; learning programmes; life course; lifelong learning; young adults

\section{Issue}

This article is part of the issue "Types of Education, Achievement and Labour Market Integration over the Life Course", edited by Irene Kriesi (Swiss Federal Institute for Vocational Education and Training, Switzerland) and Juerg Schweri (Swiss Federal Institute for Vocational Education and Training, Switzerland).

(C) 2019 by the authors; licensee Cogitatio (Lisbon, Portugal). This article is licensed under a Creative Commons Attribution 4.0 International License (CC BY).

\section{Introduction}

The character of life courses has changed in recent decades. During the Fordist period, the arrangement of work, welfare and life course were characterised as highly linear and predictable. In the Fordist life course regime, life phases were organised in a tripartite manner: education during youth, work during adulthood and retirement during old age (Du Bois-Reymond \& López Blasco, 2004; European Group for Integrated Social Research [EGRIS], 2001). Scholars such as Walther and Stauber (2006) have questioned this assumption, however. Transitions from youth to adulthood, as well as from education to employment, have become more complex and fragmented, a phenomenon referred to as "destandardisation" (cf. EGRIS, 2001). Today, life courses are understood as less linear, with reversible "yo-yo" movements (cf. EGRIS, 2001; Walther, 2006) during transitions. For example, these movements could take the form of undertaking training, being employed in a temporary job, being unemployed, being retrained and being employed in a different job (cf. Du Bois-Reymond \& López Blasco, 2004).

Life courses are also heavily influenced by the institutional configuration of the welfare state. Cultural patterns as well as structural factors interact with insti- 
tutional elements. The opportunity structure (Roberts, 2009) in which young adults make their decisions and which enables or constrains their choices is the result of the interaction of various dimensions, such as the labour market and the educational system, but also the welfare system, broadly conceived. Walther $(2006,2017)$ compiles and enlarges the typology of life course regimes by examining the interdependence among structural and institutional factors (i.e., welfare regimes and the educational system), as well as cultural patterns (i.e., conceptions of youth and narratives about transitions) across different levels of social reality, from micro to macro, and orienting programmes that address transition points in life courses.

Walther's typologies (2006, 2017) distinguish five different transition regimes: universalistic, liberal, employment-centred, sub-protective or underinstitutionalised, and post-socialist. Whereas Austria is a continental country characterised as an employmentcentred transition regime, Spain belongs to the underinstitutionalised regime. In countries classified as employment-centred transition regimes, the education system is more selective and has different tracks. Vocational Education and Training (VET) plays a central role and is relatively standardised, reproducing a highly regulated employment regime. Labour markets are standardised, and young adults who undergo yo-yo transitions must navigate restricted options for individual choice and strong demands. Countries associated with the subprotective or under-institutionalised transition regime, such as Spain, in contrast, have a low percentage of standard work arrangements and a high rate of unprotected living conditions. This creates a 'dualistic' welfare regime in which the family and informal work play a significant role. School is structured comprehensively but still in fact produces differentiation processes. Vocational Education is weakly developed and largely provided by professional schools. Lack of training and labour market segmentation contribute to very high rates of unemployment. Segmented labour markets produce populations with different characteristics, and skilled occupations and divergent occupational areas are subject to different risks of social exclusion (Du Bois-Reymond \& López Blasco, 2004). For instance, segmentation in the Spanish labour market is divided into permanent and temporary jobs (García-Mainar \& Montuerga, 2019), as well as fulltime and part-time jobs in combination with movements into and out of unemployment. Part-time jobs and such movements affect women especially (Blázquez \& Moral, 2014). Young adults experiencing these yo-yo transitions depend greatly on family support, as they receive almost no significant support from the state (Walther, 2006).

A life course perspective and, more specifically, the bounded agency and projectivity approaches, are a useful analytical lens through which to explore and analyse agency and opportunity structures, which are interrelated and determine the life course and its transition points (Heinz, 2010). This article explores the decisions of young adults in a transition phase from unemployment to employment who are enrolled in different public lifelong learning (LLL) programmes connected to the labour market. These programmes provide apprenticeships or training courses in the functional regions of Vienna (Austria) and Malaga (Spain). Functional regions are analytical units used in the YOUNG_ADULLLT project, based on spatial, functional dynamics (Lowden, Pandolfini, \& Parreira do Amaral, 2018).

Within the European Union (EU), the idea of LLL has been developed at policy level through the Lisbon Strategy and the Education and Training 2010 programme (Nóvoa, 2010). The Education and Training 2020 programme, a framework for cooperation between EU Member States for the period 2010-2020, is based on an LLL approach and has strengthened this trend, building on the achievements of the 2010 programme.

LLL policies are characterised by the EU as purposeful activities with similar goals and objectives: they stress primarily economic goals and growth but also social inclusion and personal fulfilment (Alves, Neves, \& Gomes, 2010). A recent analysis showed, however, that LLL policies and programmes across Europe were oriented to the idea of increasing employability and economic growth (Kotthof et al., 2017). This orientation is also reflected in the way young adults perceive the programmes, as described by Kovacheva, Jacovkis, Startari and Siri (2018).

The EU fosters LLL policies that promote and provide diverse types of education and learning. For instance, they include general and vocational settings, and formal, non-formal and informal contexts, spanning preschool to higher education. Adults and young adults are their main target groups, to a greater extent than children or the elderly (Alves et al., 2010). This wide range of LLL policies-and therefore also of LLL programmesincludes education and training programmes that seek to address the unemployment-to-employment transition of young adults. Some of these programmes, such as those included in this article, are closely related to the VET sphere and to non-formal education settings.

Examining young people's biographies, the way they are influenced by structural, institutional and cultural factors and the manner in which young adults interpret and use the different pathways enables us to search for patterns in the ways in which they use LLL programmes. To understand the decisions that young adults take concerning their participation in an LLL programme, we want to explore:

(1) How their past experiences influenced their decision to take part in an LLL programme;

(2) What role these programmes played in their life course;

(3) How young adults imagine their future.

Our main contribution consists of highlighting young adults' voices and perspectives by exploring the biographies of LLL participants in Vienna and Malaga. A country- 
comparison provides useful information regarding similarities and differences in contextual information that can help to better understand the role of structural, institutional and cultural factors. We assume that comparative cross-national analysis will help to depict how different contextual conditions relate to young adults' decisions and projections about their future. This research aims to advance understanding of ways the biographies of young adults reflect the transition regimes differently and how LLL programmes shape their lives in relation to their opportunity structure, past experiences and future plans.

\section{Theoretical Framework}

\subsection{Bounded Agency and the Projectivity Approach}

Individuals negotiate their agency with the structures surrounding them in changing landscapes, characterised, for instance, by changes in the labour market. People's lives are connected to these changing living conditions. Agency (Evans, 2007) is understood as bounded, as temporally embedded and as a socially situated process in which past experiences and future possibilities are reformulated within the contingencies of the present moment. Agency can thus be perceived as a dynamic and temporal process influenced by the environment (Evans \& Biasin, 2017). Past trajectories and transition outcomes, identity development, personal interests and projections about the future, and people's perception of their opportunities become relevant to their decision processes (Evans, 2007).

The projectivity approach (Emirbayer \& Mische, 1998) proposes an analytical lens for exploring the relation between past, present and future. Expectations and aspirations for one's future are shaped by the agency influenced by the past (i.e., previous experiences of patterns of behaviours), moderated by the present and oriented towards the future. While the past is revealed in action as habitual or routine practices, the present is the agency visible in deciding on and executing concrete actions, and the future frames the imagination and creation of the possible, for instance, through the actor's hopes, fears and desires for the future. When young adults construct their narratives, projectivity serves as a framework for their life course. In short, projections are imaginations about the future that guide current behaviour, which in turn shapes interrelated and intertwined outcomes. Horizons of action are different in different contexts (Biggart, Järvinen, \& Parreira do Amaral, 2015). The projectivity approach thus helps us to analyse individuals' projections, which can vary along different dimensions, including clarity, intentionality, imagined order and the timing of events (Emirbayer \& Mische, 1998).

\subsection{Bounded Agency, Projectivity and Enrolment in an LLL Programme}

The character of life course transitions has changed over the last 60 years (Du Bois-Reymond \& López Blasco,
2004). These transitions are influenced by different societal trends, such as the inflation and importance of educational credentials, diversification in coupling forms (e.g., remarriage), reductions in welfare state provision, structural unemployment and labour market de-regulation, which resulted in increased enforced flexibility and temporary employments (Brückner \& Mayer, 2005).

Although life courses are now understood predominantly as de-standardised, most LLL policies and programmes seem to have been developed according to the scheme of standardised and linear life courses (Kotthof et al., 2017). The introduction of LLL policies can be understood as one of policy makers' attempts to govern youth transitions. These policies cover vocational settings, including formal and non-formal contexts (Alves et al., 2010). In both formal and non-formal settings, VET can be included among them. VET is one of the instruments supporting the transition from school and training to work; it also eases the transitions of those who inhabit "wild zones" (i.e., young adults who face greater risks due to increasing uncertainty) and helps them to navigate to more secure "tame zones" (Kelly, 1999). People can therefore use social and educational programmes to overcome different structural constraints (Evans, 2007). They can understand LLL programmes as providers of new life-course opportunities, for instance, in relation to their labour market integration.

Young adults frame the decision to enrol in an LLL programme by considering their past trajectories, their projections about their future and the contingencies of the present moment (Emirbayer \& Mische, 1998; Evans, 2007). This decision is influenced and shaped by wider contextual factors, such as the welfare state or the labour market (Evans \& Biasin, 2017; Walther, 2006). Pawson (2006) describes programmes as embedded in different levels (macro-meso-micro) and dimensions of social reality. Social change also depends, however, on the characteristics of their participants.

\subsection{Young Adults' Living Conditions in Austria and Vienna}

As explained in Section 1, Walther's typology of transition regimes describes Austria (Vienna) as an employmentcentred country and Spain (Malaga, Andalusia) as subprotective (Walther, 2006) or under-institutionalised (Walther, 2017). Because typologies are conceived as static, we present the following data on the living conditions of young adults in both regions to refine them.

According to Eurostat data for 2017, rates of Early School Leaving (people aged 16-24 with an ISCED 0-2 classification) differed substantially in Andalusia (23.5\%) and Vienna (9.6\%). Moreover, the proportion of the age group 30-34 years with an ISCED 5-8 classification was lower in Andalusia (32.3\%) than in Vienna (50.4\%).

As is to be expected from the typology, the unemployment rates are substantially higher in Andalusia than in Vienna, especially for young people (Figure 1). 
Youth unemployment rates (15-24)

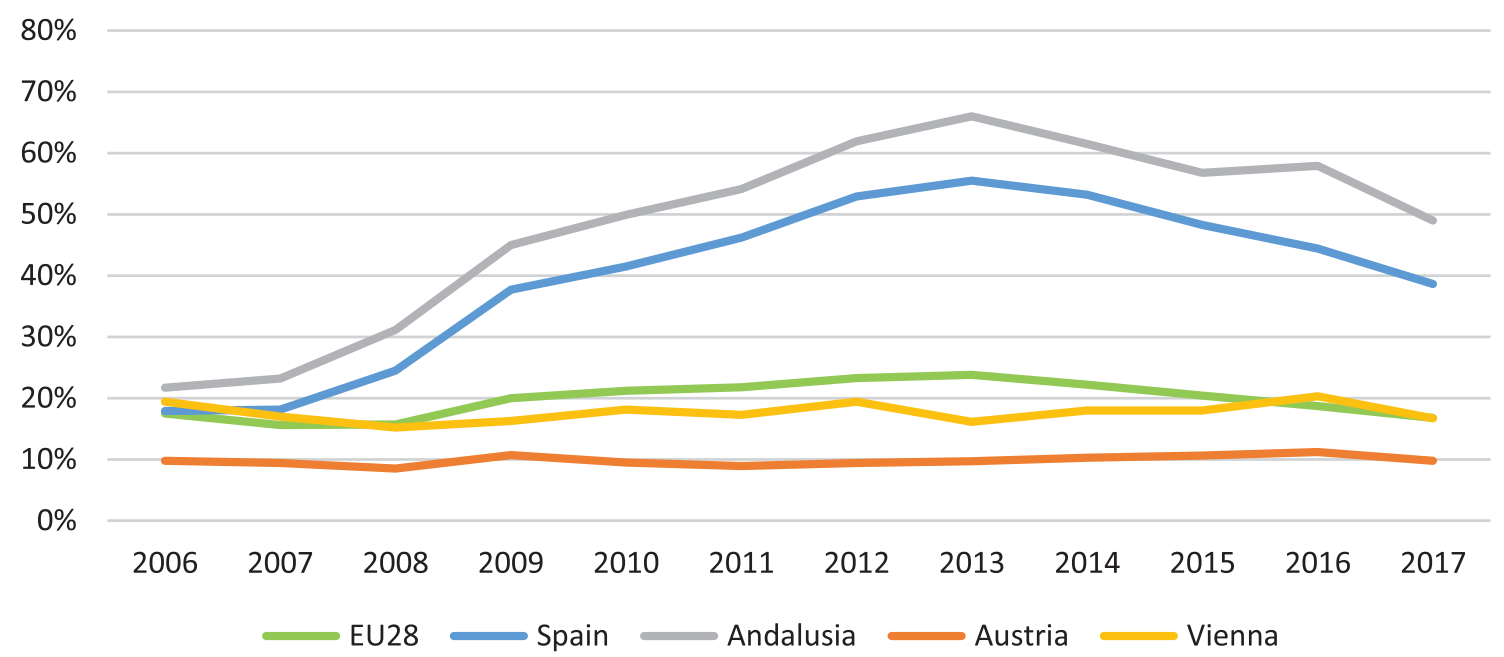

Figure 1. Youth unemployment rates, age group 15-24 years. Source: developed by the authors with Eurostat (2019) data.

Due to a lack of reliable paths to the labour market, which is characterised by situations of generalised unemployment or over-qualification, gaps between the spheres of education, training and labour are higher in under-institutionalised regimes than in employmentcentred ones, where youth transitions are more structured. Less-institutionalised transition systems may be related to both greater risks and a wider scope for agency and individualised decisions by young people during their transitions (Evans, 2007), as these people can identify more areas in which to perform alternative strategies for labour integration. Young adults in under-institutionalised regimes thus tend to bridge these gaps actively during their less-institutionalised transitions through self-employment, volunteer work or higher mobilisation of social capital, such as personal contacts (Walther \& Stauber, 2006). Self-employment rates increased during the 2007 economic crisis, from 21.8\% (2006) to $28.6 \%$ (2017) in the functional region of Malaga (Fundación Málaga Desarrollo y Calidad, 2019).
Following Walther (2006), labour markets in employment-centred regimes may be divided into a core with higher levels of standardisation and protection and a more precarious periphery, due perhaps to the fact that young adults with lower ISCED-level credentials are much more vulnerable to temporary contracts than those with higher ISCED levels (Figure 2). In line with the typology, the Andalusian labour market shows higher rates of temporary jobs, which affect all ISCED levels (Figure 2), combined with other forms of precarious and informal employment and over-qualification. For example, Andalusia showed a $51.2 \%$ of over-qualification in the first six months of 2017 , higher than the $47.7 \%$ of the Spanish national average (Consejo de la Juventud de España, 2017). In under-institutionalised regimes, young adults experience such forms of informal and temporary jobs as a way to achieve some independence from the family (Walther, 2006).

In countries in the employment-centred regime category, social security is provided by both family and the

Temporary work rates (15-24)

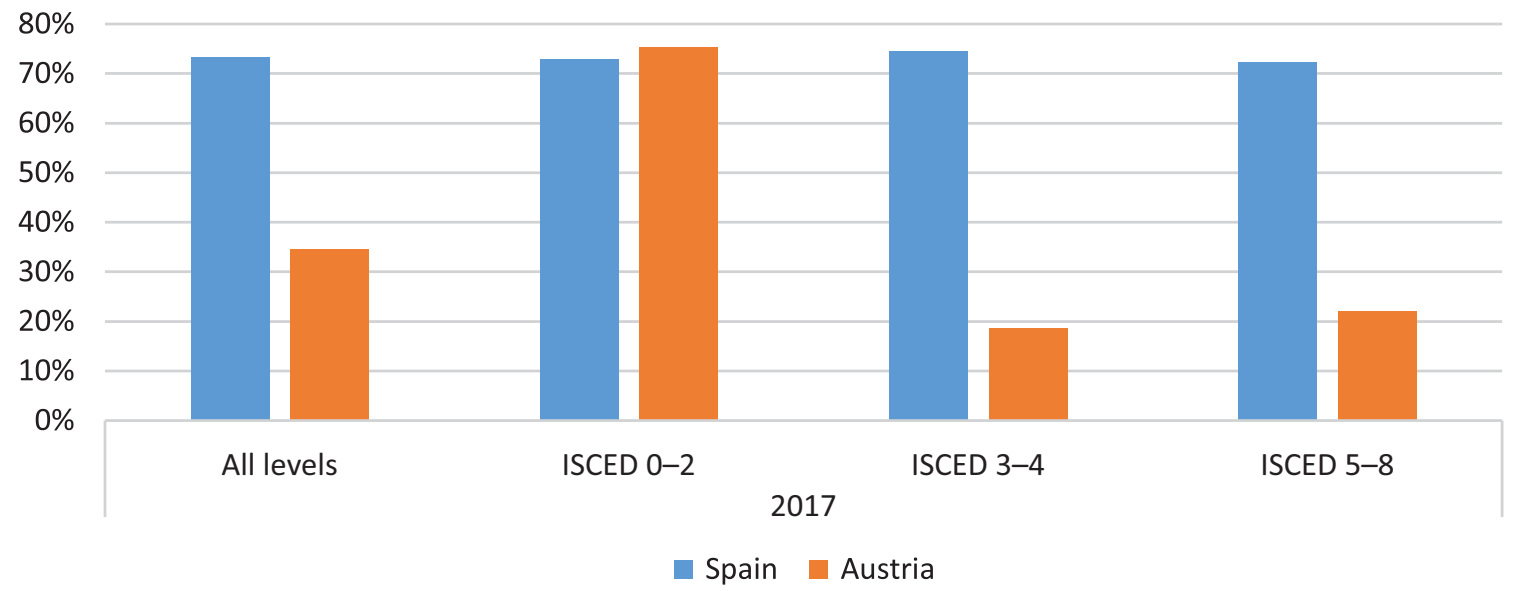

Figure 2. Temporary work rates, age group 15-24 years. Source: developed by the authors with Eurostat (2019) data. 
state, although state aid is viewed with ambivalence by young adults. In countries in the under-institutionalised regime, in contrast, family is the centre of social security (Walther, 2006). Family works as a "social shock absorber" because young adults receive no substantial social benefits from the state (Walther \& Stauber, 2006). In Spain, family support provides young adults with some security and flexibility during their transitions, and can act as a "waiting hall" (Du Bois-Reymond \& López Blasco, 2004). This protracted economic or habitational dependence on families, in combination with labour market characteristics such as high youth unemployment and other structural deficits (e.g., social services), contributes to labelling young adults as disadvantaged (Walther, 2017).

In employment-centred regimes (Walther, 2006), in contrast, opportunities are more dependent on institutions and structures. Young adults are more inclined to believe that the qualifications and educational paths to labour market entry offer better prospects, as reflected in the low rates of unemployment and better labour conditions (i.e., contracts). This power attributed to educational and training-system structures and their paths to a standardised labour market may, however, be associated either with individuals' lower self-responsibility in the case of failure or with processes that stigmatise 'the losers' who follow less-valued pre-vocational pathways (Walther, 2006).

\section{Methodology}

We performed an in-depth literature review of the concepts and themes relevant to the research question and used these to ground the research design. The data analysis method chosen consists of two research steps. First, by examining the biographies of young adults in Vienna and Malaga and describing their main trajectories in different life domains, such as education, work or family, we describe and analyse their decisions to enrol in one of the available LLL programmes and their transition, taking contextual conditions into account (cf. Eurostat, 2019; Walther, 2006, 2017). Second, we analyse their projections about their imagined futures.

\subsection{Sample}

Our sample consists of 10 young adults from Vienna and 8 from Malaga who were taking part or had taken part in different programmes in these regions (Table 1). The initial sample from Malaga included 10 young adults, but two were eliminated because the programmes in which they participated belonged to the formal education system and not to the public LLL programmes in the labour sphere included in this article and described below.

In Malaga, the Workshop School Programme (2013 edition) is exclusively for unemployed young adults aged 18-25 and forms part of the wider Vocational Training for Employment subsystem in Andalusia. Due to suspicions about funding control in this subsystem, the new edition of the programme was suspended and did not resume until 2018. Workshop schools give priority to individuals who have a deficit in education/training credentials and/or belong to a specific vulnerable group, such as those considered to be at risk of social exclusion. It is an interesting programme because it provides a comprehensive range of activities. Further, it provides young adults with courses to become athletic instructors and teaches them about various topics, related, for example, to gender equality or environmental education. It also offers them the opportunity to prepare for compulsory secondary education examinations. The programme was structured around a one year training period (one year) and a paid apprenticeship (six months) in the same organisation that implements it.

The Vocational Training Courses (2017 edition) have the same two-part structure but focus on professional training, with apprenticeships in local companies. These courses are not just for young adults, although $50 \%$ of

Table 1. Distribution of young adults (with fictitious names) in both regions, by programme in which they are enrolled.

\begin{tabular}{|c|c|c|c|}
\hline \multicolumn{2}{|c|}{ Vienna } & \multicolumn{2}{|c|}{ Malaga } \\
\hline Programme & Young adults & Programme & Young adults \\
\hline \multirow{5}{*}{ Just Integration } & Ahmed & \multirow{2}{*}{ PICE } & Sofía \\
\hline & Faisal & & Pedro \\
\hline & Jana & \multirow{4}{*}{ Vocational Training Course } & José \\
\hline & loana & & Mario \\
\hline & Musa & & Antonio \\
\hline \multirow{5}{*}{ Back to the Future } & Daniel & & Pablo \\
\hline & Habib & \multirow{2}{*}{ Workshop School } & Mónica \\
\hline & Jakob & & Cecilia \\
\hline & Alexander & & \\
\hline & Lena & & \\
\hline
\end{tabular}


the positions are reserved for people aged 18-29. Entry criteria vary depending on the course, starting with no requirement for a compulsory secondary education qualification. The courses include traditional crafts, such as gardening and carpentry. The third LLL programme in Malaga is the Comprehensive Programme for Qualification and Employment (PICE; 2017 edition), framed by the EU Youth Guarantee Scheme and aimed at unemployed young adults aged 16-29. After initial orientation sessions, participants may enrol primarily in a range of attendance-based (185 hours) and online (100-150 hours) training courses on a great variety of topics, including language and technological skills for specific professions.

The young adults in Vienna were enrolled in two different programmes (2017 editions). The Back to the Future programme was oriented specifically to Viennese young adults aged $18-24$ who were dependent on needsoriented subsidies and registered at the employment service but had not yet managed to find a job, despite participating in training and an active job search. Participants were provided with coaching, training and transitional employment for a maximum of two years. The project was conceived for young adults with little work experience and special needs who had encountered obstacles to finding long-term employment. The idea was to encourage participants and improve their pre-existing skills through acquisition of additional competence to prepare them for more highly-qualified tasks.

The second programme was JUST Integration. The target group was young adults from Vienna aged 18-30 who faced difficulties entering the labour market due to overlapping disadvantages. One particular target group of this programme was young refugees who had been granted asylum. The young adults were provided with individual support in the form of short apprenticeships based on previous work experience to foster their reintegration into the labour market for six months and ease their transition into work.

\subsection{Data Collection}

The interviews were performed within the YOUNG_ADULLLT project. Young adults were contacted through snowball sampling with the help of professionals in charge of the programmes in which they were participating. Sampling criteria were based on (Rambla, Jacovkis, Kovacheva, Walther, \& Verlage, 2018):

(1) Identifying relevant regions and programmes in the countries that participated in the project-in this article, Vienna (Austria) and Malaga (Spain);

(2) Selecting different young adults (as well as managers, street professionals and experts) who had participated in the same LLL programmes, to provide different accounts of them;

(3) Ensuring diversity among young adults in terms of age (18-29 years of age), gender, ethnicity and origin.
Semi-structured interviews were conducted and transcribed in 2017 on the basis of a common interview guide circulated among YOUNG_ADULLLT project partners to strengthen comparability. The first question was a narrative open question about young adults' lives to obtain information about their life stories. Further questions were then asked about some of the issues raised during the narratives, such as their imagined life plans.

\subsection{Data Analysis}

Data analysis was performed following Corbin and Strauss's (1990) Grounded Theory (GT) principles. Informed GT (Thornberg, 2012) recognises that researchers who work with GT principles usually have previous knowledge in the field of their research and that this knowledge is reflected in one way or another in the research and data analysis. The data can thus be explored through the lenses of previous knowledge and pre-existing theories. We used the theoretical framework of bounded agency and projectivity to explore the empirical data in order to feed and expand existing theory on youth transitions. The data analysis started from this article's research questions. Different codes of analysis were introduced, codes closely related to the literature on life course as well as to the research questions, especially those in relation to their experiences in the LLL programme or their future dreams. Table 2 provides a detailed list of the codes employed.

Table 2. Codes for analysing the young adults' interviews.

\begin{tabular}{cc}
\hline Previous trajectories & Projections \\
\hline Family & \\
Education & \\
Health & \\
Labour market experiences & Future dreams \\
Reflexivity towards skills & Specific next steps \\
LLL programme & \\
Experience in LLL programme & \\
Other past experiences & \\
\hline
\end{tabular}

Once the interviews were coded, we ordered the different transitions experienced by each of the young adults in our sample chronologically. Each 'life as narrated' was thus interpreted against the backdrop of its contextual conditions, past transitions and projections about the future, with attention to the speaker's accounts of transitions and decisions, especially the transition into LLL. Later, two comparisons were made, one within the regional sample and another with the samples from both countries, to identify and analyse patterns of similarity and difference based on the codes and research questions explored. Attention was also paid to other sociodemographic issues, such as age, migration background and maximum education credentials (vocational/academic route) obtained. 
Comparison in life course studies requires moving both from the macro to the micro and through different dimensions and contexts, such as education or the labour market. Some information is likely to be lost in the process of reducing complexity. We recognise this fact, as well as the risk of being guided considerably by previous theories, as potential limitations of this study.

Nonetheless, the comparative analysis proposed of these two samples of young adults from two quite different countries and regions (different, for instance, in transition regimes and living conditions) can be very useful in depicting the different contextual conditions and how they influence agency. Furthermore, the diversity of our sample can improve understanding of the diversity and complexity that define the social world, and thus the LLL programmes themselves and the biographies of their participants.

\section{Results}

\subsection{The Cases of Pablo and Alexander}

We provide in-depth description of two cases: Pablo from Malaga and Alexander from Vienna. These individuals are similar in age, gender and level of educational credentials obtained (Early School Leaving situation). Whereas Early School Leaving is quite common among young adults in both regions, migration is more common among the Viennese young adults. These characteristics of our sample, such as a lack of educational credentials and/or qualification, suggest that the individuals could face difficulties in their later life course. For instance, they could be more prone to disqualified trajectories into the lessprotected segments of labour market, with higher risks of unemployment and worse labour conditions.

The narratives of Pablo and Alexander serve as an entry point for exploring the complexity that characterises not only their past trajectories but also their decisions and experiences based on their participation in an LLL programme and their projections for the future. Their narratives reflect the relevance of different characteristics of the transition regimes and broader living conditions, such as the importance of family, the informal economy in Spain and state support in Austria.

\subsubsection{The Case of Pablo}

Pablo, age 21, grew up in Malaga. He says that he never liked to study and struggled to pass each year of primary and secondary education, although he never had to repeat a year.

The Spanish education system is structured in a comprehensive way and is compulsory until the age of 16. At 16 , Pablo decided to enter post-compulsory education, academic track. Pablo was convinced by his parents' expectations and by his own perception that there was less opportunity to enter the labour market than in previous years, when the construction sector was stronger. Pablo dropped out of post-compulsory education after three months, however, and has since undertaken a variety of yo-yo movements. He experienced Not in Education, Employment, and Training (NEET) situations and gained informal and precarious work experience to support his parents, since his father was unemployed. Pablo also attempted to return to formal Vocational Education, but he again dropped out because he felt he was lagging behind his classmates. This decision was triggered not only by finding the theoretical content quite difficult but also by his grandfather's death.

Pablo characterises his daily routine during the NEET situation as monotonous, just "staying at home" and smoking plenty of cannabis. Pablo said he was "willing to do something" to change the situation but was not successful. He had a personal conflict with his mother at the time because "she wanted him to do something" else. He went to live with his grandmother to help his family care for her.

Pablo believes that changes must come from reflecting on your own situation and taking decisions. After reflecting, Pablo felt he "would be going nowhere" if he continued "to live life this way". Because his projections for the future did not appeal to him, he struggled to find a job as soon as possible. He believes that work is necessary to be economically independent.

Pablo's father told him about the Vocational Training Courses. Pablo liked the idea and decided to apply to one. His past work experiences made him realise that he preferred active jobs like the one for which he is now being trained. He portrays himself as happy with his current training. He values his relationship with his classmates and teachers greatly, as they help him to acquire specific skills and practical knowledge close to the professional world.

Pablo is aware of the generalised unemployment in Andalusia and knows that young people with lower educational credentials have fewer job opportunities today than a few years ago (i.e., construction). Because he has already experienced a yo-yo transition and precariousness, he seems to be working harder to avoid repeating such experiences. Pablo believes that this course will allow him to find new work opportunities, but there is no guarantee that he will be able to find a job due to the difficult labour market.

In the future, Pablo wants to work as a gardener, and he is even considering self-employment. If he cannot work as a gardener, he will try to find other jobs. If neither option works, he does not reject the idea of receiving more training or even returning to formal education. As a last option, Pablo has not abandoned his professional dream of joining the army, but he feels discouraged due to the highly competitive application process.

\subsubsection{The Case of Alexander}

Alexander, 23 years old, was born in Vienna but moved to Burgenland. He portrays himself as a very shy person 
who benefits from other people's support to improve his socialisation. He says that he did not receive as much support and personal care as he needed because of the high student-teacher ratio in his class at school. This lack of attention, combined with his self-presentation as a lazy child and with episodes of social anxiety, made it difficult for him to focus on school. His interview narrative explains that the early stages of his educational career were a "difficult period".

After finishing Lower Secondary Level studies at the age of 14, Alexander moved to a College for Higher Vocational Education in the capital city of Burgenland, where he lived with some of his friends. His parents convinced him to make this move towards a "more vocationallyoriented" programme, despite the fact that Alexander wanted to continue to study in the Academic Secondary School, Upper Cycle. He felt he was not talented in manual and technical work, so he dropped out of the course.

Alexander also did an internship in a supermarket, during which he contemplated an apprenticeship, influenced in part by his peers: friends, neighbours and family. He decided to attend a private higher-level vocational school to study social professions and gastronomy. Alexander indicated that his experience in this school was supportive, especially the relationship with his teachers, and that this increased his motivation to learn and enjoy his time there. Alexander's parents' divorce was, however, a critical juncture in his life course, as it led to financial problems in his family. He abandoned these studies in the fourth of five years because he could no longer afford the tuition.

After having to leave school, Alexander was required to take different courses offered by the Austrian Public Employment Service. He is quite critical of these courses, which he perceived as useless and a waste of time. He could not participate in either a course or a form of training that would support him.

A friend who had participated in the LLL programme Back to the Future a year earlier told Alexander about this opportunity. A crucial factor in his decision to apply for the programme was that he could not find a job after doing his civil service and was unemployed for six months. Applicants to Back to the Future have generally registered in the Austrian Public Employment Service, which assigns young adults to the programme. The participants receive financial support from this Employment Service to cover their living costs. Back to the Future seeks labour market integration for young adults who are currently receiving a basic subsidy to improve their employability by means of intensified coaching, training and transitional employment. Alexander portrays himself as happy in the programme, which he finds quite stimulating and which provides him with a structured work routine. Moreover, its timetable allows him to attend evening classes to obtain his general qualification for university entrance (A-Levels).

The Back to the Future programme helped Alexander gain more self-confidence and organise his daily life. In the future, he dreams of being a psychotherapist or working in human resources management. Alexander plans to finish his schooling, study at the university and, most importantly, obtain a stable job.

\subsection{Decisions, Experiences and Expectations Concerning the LLL Programmes: Insights from Bounded Agency and Projectivity}

Starting from the cases of Pablo and Alexander and introducing other information about the life courses of the rest of the sample, this section will develop in greater depth some of the main themes identified through the analysis. The themes, which relate to some of the richer pieces of information identified, were chosen to expand existing theory on youth transitions and answer the research questions. For reasons of space, other topics, such as "support during transitions" or "standardised or normal life course", are not addressed separately.

\subsubsection{Looking for Work, Training and Personal Opportunities}

The LLL programmes analysed attempt to ease the transition to the labour market. In Andalusia, they provide training and in some cases apprenticeships or paid work experience. In Austria, they also provide coaching and training to unemployed young adults with difficulty finding a job or entering the labour market.

Despite these differences in their activities and target groups, the young adults in both regions commonly refer to the role these programmes play in their life courses by providing them with new opportunities (see Table 3).

The participants perceive these opportunities differently. First, the opportunities can be a steppingstone or gate keeper to new pathways into the labour market. This is the case of Sofía, a young adult woman with tertiary education who experienced various yo-yo movements, such as migrating abroad, returning to Spain, and combining study and work. Sofía expects to use PICE to diversify her skills to open new job possibilities. Like Sofía, Pablo expects to find a job that suits him after the programme. Ahmed, a Syrian refugee in Austria, expects to obtain new training credentials from enrolling in JUST Integration.

Second, opportunities are related to possibilities of being trained for or gaining working experiences in jobs for which participants could not previously be trained. José is currently enrolled in a Vocational Training Course on gardening. He had previously tried to access formal Vocational Education in this field, in which he has always wanted to work, but was not able to do so. Antonio was also unable to access other earlier formal education he liked because he did not fit the entry criteria (he had not validated his educational credentials from Latin America in Spain). He is finally being trained in carpentry, an area related to his personal and professional interests. 
Table 3. Meaning behind the decision to enrol in an LLL programme: Perceived opportunities.

\begin{tabular}{|c|c|c|}
\hline \multicolumn{3}{|r|}{ Malaga } \\
\hline Young adult & & Meaning \\
\hline Sofía & \multirow{7}{*}{ Open opportunities } & Open-door strategy: diversify options \\
\hline Pedro & & In the future, find a job to support his brother "who has problems" \\
\hline José & & \multirow{2}{*}{ Finally found a chance to be trained and work in the professions he likes } \\
\hline Antonio & & \\
\hline Mario & & Programme as a "safety net" if he does not achieve his professional dream \\
\hline Pablo & & Right choice to escape the NEET situation and change routines/habits \\
\hline Cecilia & & Way to "rebuild her life" and "become something" \\
\hline Mónica & Personal development & Way to "open up". To be trained in an area she likes \\
\hline \multicolumn{3}{|r|}{ Vienna } \\
\hline Young adult & \multicolumn{2}{|r|}{ Meaning } \\
\hline Ahmed & \multirow{7}{*}{ Open opportunities } & \multirow{7}{*}{ Open-door strategy: Diverse options } \\
\hline loana & & \\
\hline Musa & & \\
\hline Daniel & & \\
\hline Jakob & & \\
\hline Alexander & & \\
\hline Lena & & \\
\hline Faisal & \multirow{2}{*}{$\begin{array}{l}\text { Consolidate/improve his } \\
\text { position in his current job }\end{array}$} & \multirow{2}{*}{ Professional and personal growth } \\
\hline Habib & & \\
\hline Jana & & "Last chance" for a labour market opportunity \\
\hline
\end{tabular}

Finally, opportunities are related to the participants' personality development. This is the case of Pablo, who used the programme not only to diversify his job opportunities but also to overcome his NEET situation and change his habits. Cecilia reflects on past experiences marked by times of lack of support from her parents, Early School Leaving and troubles entering the labour market or other training courses. She enrolled in the programme in hopes of "rebuilding her life" and "becoming something" and to learn new skills. Mónica suffered from bullying at school. She decided to enrol not only to be trained but also to learn how to "open up".

Faisal and Habib are both refugees from Syria who moved to Austria after the European migrant crisis in 2015. Faisal hopes that participating in the LLL programme JUST Integration will help him not only to grow professionally, but also to develop his language skills, which he finds important to finishing his training and having a good future in Austria. Habib perceives the programme similarly. His involvement in JUST Integration is a steppingstone to a better future in general and to "becoming a better person" in terms of work ethic and eagerness. Lastly, the goal was to get a better job.

\subsubsection{Degrees of Clarity in Young Adults' Projections about Their Future}

Young adults from both regions share imagination of a normal and standardised life course. They dream of a life that follows a specific plan: having a job (and, therefore, earning enough money to enjoy economic stability), building their own family and home, and being independent.

Young adults from Malaga and Vienna generally differ, however, in the clarity of their projections about their future, especially in their imagined next steps after participation in the LLL programme. This difference is reflected in the different types of transitions and risks they imagine they will face when pursuing their professional and personal objectives. While the Andalusian young adults tend to prepare alternative plans in case they cannot find a job, the Viennese young adults only discuss a few alternative pathways to employment after completing the programme. All seem to be aware that the programmes' functioning is influenced by their wider contextual conditions, such as the higher youth unemployment in Andalusia and the more institutionalised transitions and better job prospects in Austria. They tend to 
differ in their degree of confidence in the potential of LLL programmes to contribute to their labour integration.

In this vein, Ioana, a Romanian migrant, and Musa, an Afghan refugee, have obtained secondary education but have experienced more yo-yo movements than Alexander in their previous transitions. loana hopes to be hired in the company where she is doing her apprenticeship, and Musa wants to take the final craftsman's examination in his apprenticeship to find a job.

In Malaga, Mónica and Cecilia are interesting cases. They finished their participation in the programme two years ago and expected to find jobs on completion, but they are still unemployed. Both have again experienced yo-yo movements during their transition. They do not discount returning to training or to the formal education system. Like Pablo, they make multiple projections about their future, also preparing alternative plans to achieve labour market integration.

\subsubsection{The Restorative Role of LLL Programmes}

The restorative role of the LLL programmes is important for some young adults. Positive aspects are teachers' high degree of involvement in participants' learning situation, a supportive relationship with peers, the learningby-doing approach and the practical character of the programme. All of these aspects are reflected in the cases of Pablo and Alexander.

Other young adults also describe themselves as being happy that they had enrolled in the programme. Mario says, for example, "I am doing what I have never done before, that is...feeling happy when I come here to study". In the interviews, the young adults say they have been pleasantly surprised. Some even talk about the programme as different from their past encounters with school or their attempts to return to the formal education system. Here, their past experiences are significant.

Mónica and Cecilia believe that their self-confidence increased during the programme, where the professionals acted as "significant others". José thinks that he is at the best point in his life, since he finally has the opportunity to be trained as a gardener. Daniel tried twice to obtain his general qualification for university entrance, but he failed. He experienced several rejections in his job search because he had neither educational credentials nor work experience in the formal labour market. He considers his participation in Back to the Future as a major achievement. It is not only providing him with new work opportunities but also is helping him to gain self-confidence.

In contrast to this perception of Back to the Future, many Austrian young adults like Daniel consider the courses proposed by the Austrian Public Employment Service as a waste of time because the activities are not useful. The uselessness seems to be related to their perception that those courses have not helped them, not provided them with tools to foster their transition into the labour market, or not contributed to their personal growth: "That was a real waste of time...in the end, the courses didn't help. It was about daydreaming and really, really weird, very odd things, what they offered unemployed young people".

\section{Discussion and Conclusion}

The aim of this article was to highlight young adults' perspectives by exploring the biographies of participants in LLL programmes in Vienna and Malaga. Giving voice to young adults is useful for understanding the ways they use and interpret their pathways during transition points (Walther, 2017). By analysing the interviews, we show how contextual conditions and bounded agency not only are interrelated in individuals' actions (Evans \& Biasin, 2017) but also shape the young people's projections about their futures, a process where past experiences also become relevant (Emirbayer \& Mische, 1998).

We used the cases of Pablo and Alexander as entry points to explore the research questions and disentangle their complexity, as these individuals' experiences reflect different characteristics of their respective life course regimes (Walther, 2006, 2017). Moreover, the biographies were embedded in contextual data (e.g., Eurostat, 2019) about young adults' living conditions in their regions to interpret the biographies in greater depth.

Based on transition regimes typologies, young adults in different contexts experienced different sources of support during their transitions (Walther, 2017; Walther \& Stauber, 2006): family is central in the case of Pablo, as are both family and state in the case of Alexander. Social capital and networks, such as family or friends, were also significant in their transition into the LLL programme, for instance, in informing them of its existence.

Labour market characteristics were also relevant (Walther, 2006). Pablo experienced and suffered the consequences of his yo-yo transitions (EGRIS, 2001), marked by a lack educational credentials in a precarious labour market. His past influenced his present actions and future imaginations. Pablo also mentions his negative routines during his NEET situations and the absence of appealing projections of the future had these routines continued. Moreover, he has prepared several alternative plans in case he cannot find a job after the programme, although he expects ultimately to achieve stability.

Alexander, in contrast, can count on public subsidies while he is unemployed or enrolled in his programme. He does not seem to feel either pressure or fear about the possibility of experience a transition into the most precarious periphery of the Austrian labour market (Walther, 2006), since the state provides a variety of benefits to help him. After completing the program, he wants to return to formal education. Alexander seems certain that he will be able to achieve stability and re-standardise his life course, as he has not thought about alternatives in case his plans fail.

In our opinion, projections (Emirbayer \& Mische, 1998) about having a standard or normal life course 
(Walther, 2017) are related, on the one hand, to the high degree of institutionalisation of transitions in Austria (Walther, 2006). Viennese young adults' projections are influenced by the belief that the state will help them in all events and that following certain education/training patterns, such as going through the VET system, will enable them to achieve better labour positions and a standardised life course. The same projections among the Andalusian young adults could show, however, their desire to escape from forced participation in temporary jobs, which affects all ISCED levels (Eurostat, 2019).

The success of these programmes depends not only on the contexts but also on the people with whom they are working (Pawson, 2006). The diversity of "opportunities" that our research identified drew our attention to the different roles and expected effects of these programmes as perceived by young adults in their life course (Kotthof et al., 2017; Kovacheva et al., 2018). In some cases, young adults expected to create some of these opportunities at the same time in order to find solutions to various challenges they were facing at the moment, such as trying both to find a job and "to grow" personally. After experiencing these programmes, some even talk about the programmes' restorative role in their lives. These effects depend greatly, however, on their past experiences, such as being bullied or being rejected by the labour market, as well as on the programme's resources (i.e., personal support), which must fit their needs. Other young adults, in contrast, perceive other institutions' programme activities as a "waste of time".

More research is clearly needed, especially research that attends more closely to the content and type of skills the LLL courses offer, which could activate different mechanisms to trigger change (Pawson, 2006) or explores differences related to the social class or socioeconomic status of the young adults.

Moreover, it would be interesting to perform this analysis using samples of the same country, both people who chose to take part in an LLL programme and people who did not, in order to explore how different individuals negotiate and exercise their agency in similar contextual conditions.

Nóvoa (2019) recently stated that the purpose of LLL has changed from a "right" to learn on a lifelong basis to a "duty" that supports economic growth and employability. This change has been accompanied by increased responsibility of individuals for their learning processes and success (Alves et al., 2010). Since the goals of LLL policies and programmes have become more normative, it would be interesting to hear from young adults about the significance and different meanings the programmes have to them. By giving these young adults a voice and recognising them as equal actors, we can use their reflections on their experiences to develop more sustainable LLL programmes in line with their personal interests, as well as to understand the broader role of LLL programmes. The young adults reflect not only on their skills acquisition, but also on the degree of support they received, for in- stance, from teachers and peers. They reflect particularly on how their experiences affected them and increased their self-confidence, and the opportunities that these programmes represent for pursuit of personal and professional projects.

This article should serve to remind policymakers to develop programmes that better fit young adults' interests and chains of reasoning. Our conclusion that programmes can be improved by listening to young adults follows Pawson (2006), who claims that improving these programmes ultimately depends on how their subjects receive the resources and mechanisms introduced. And as we have shown, there is no pattern for a one-size-fitsall programme; everything depends on the context, the complex interrelations of which must be untangled in order to understand the young adults' agency.

\section{Acknowledgments}

This article is based on a research project (YOUNG_ADULLLT) funded by the EU's Horizon 2020 Research and Innovation Programme, Contract Number 693167. Open access funding provided by the University of Vienna.

\section{Conflict of Interests}

The authors declare no conflict of interests.

\section{References}

Alves, M. G., Neves, C., \& Gomes, E. X. (2010). Lifelong learning: Conceptualizations in European educational policy documents. European Educational Research Journal, 9(3), 332-344.

Biggart, A., Järvinen, T., \& Parreira do Amaral, M. (2015). Institutional frameworks and structural factors relating to educational access across Europe. European Education, 47(1), 26-45.

Blázquez, M., \& Moral, J. (2014). Women's part-time jobs: "Flexirisky" employment in five European countries. International Labour Review, 153(2), 269-292.

Brückner, H., \& Mayer, K. U. (2005). De-standardization of the life course: What it might mean? And if it means anything, whether it actually took place? Advances in Life Course Research, 9, 27-53.

Consejo de la Juventud de España. (2017). Observatorio de emancipación. Versión de Andalucía (Report 14) [Emancipation observatory. Version about Andalusia]. Madrid: Consejo de la Juventud de España.

Corbin, J., \& Strauss, A. (1990). Grounded theory research: Procedures, canons, and evaluative criteria. Qualitative Sociology, 13(1), 3-21.

Du Bois-Reymond, M., \& López Blasco, A. (2004). Transiciones tipo yo-yo y trayectorias fallidas: Hacia las políticas integradas de transición para los jóvenes europeos [Yo-yo transitions and misleading trajectories: Towards integrated transition policies for young Euro- 
peans]. Estudios de Juventud, 65, 11-29.

Emirbayer, M., \& Mische, A. (1998). What is agency? American Journal of Sociology, 103, 962-1023.

European Group for Integrated Social Research. (2001). Misleading trajectories: Transition dilemmas of young adults in Europe. Journal of Youth Studies, 4(1), 101-118.

Eurostat (2019). Database. European Union Statistical Office. Retrieved from https://ec.europa.eu/eurostat/ data/database

Evans, K. (2007). Concepts of bounded agency in education, work, and the personal lives of young adults. International Journal of Psychology, 42(2), 85-93.

Evans, K., \& Biasin, C. (2017). Exploring agency, learning and identity in women's life trajectories in United Kingdom and Italy. Revista Española de Educación Comparada, 29, 15-32.

Fundación Málaga Desarrollo y Calidad. (2019). Plataforma en Red de Indicadores Socioeconómicos de la provincia de Málaga [Network platform of Socioeconomic Indicators of the province of Malaga]. PRISMA. Retrieved from www.prisma.global/ Observatorio/Sistemalnteligente

García-Mainar, I., \& Montuerga, V. (2019). The signalling role of over-education and qualifications mismatch. Journal of Policy Modeling, 41, 99-119.

Heinz, W. (2010). Life course dynamics. In C. Crothers (Ed.), Historical developments and theoretical approaches in sociology. Volume I (pp. 226-248). Paris: UNESCO-EOLSS.

Kelly, P. (1999). Wild and tame zones: Regulating the transitions of youth at risk. Journal of Youth Studies, 2(2), 193-211.

Kotthof, H. G., Gáfaro, J. F., Bittlingmayer, U. H., BoutiucKaiser, A., Parreira do Amaral, M., \& Rinne, R. (2017). International report: LLL policies and inclusion in education and work (YOUNG_ADULLLT Working Paper). Freiburg: University of Education Freiburg.

Kovacheva, S., Jacovkis, J., Startari, S., \& Siri, A. (2018). Young adults' participation in LLL and its impact on their life projects. In M. Parreira do Amaral, J. Zelinka, \& M. Schweisfurth (Eds.), Comparative anal- ysis and reporting: Comparative analysis strategy. YOUNG_ADULLLT Working Papers (pp. 91-111). Münster: University of Münster.

Lowden, K., Pandolfini, V., \& Parreira do Amaral, M. (2018). Functional regions as dynamic units: Understanding coordinated policy-making in LLL. In M. Parreira do Amaral, J. Zelinka, \& M. Schweisfurth (Eds.), Comparative analysis and reporting: Comparative analysis strategy. YOUNG_ADULLLT Working Papers (pp. 160-187). Münster: University of Münster.

Nóvoa, A. (2010). La construcción de un espacio educativo europeo: Gobernando a través de los datos y la comparación [The formation of a European educational space: Governing through data and the comparison]. Revista Española de Educación Comparada, 16, 23-41.

Nóvoa, A. (2019). How much long life is there in lifelong learning? Paper presented at the YOUNG ADULLLT Policy Seminar \& Final Conference, Lisbon, Portugal.

Pawson, R. (2006). Evidence-based policy. A realist perspective. Thousand Oaks, CA: SAGE Publications.

Rambla, X., Jacovkis, J., Kovacheva, S., Walther, A., \& Verlage, T. (2018). International qualitative analysis report (YOUNG_ADULLLT Working Paper). Barcelona: Autonomous University of Barcelona.

Roberts, K. (2009). Opportunity structures then and now. Journal of Education and Work, 22(5), 355-368.

Thornberg, R. (2012). Informed Grounded Theory. Scandinavian Journal of Educational Research, 56(3), 243-259.

Walther, A. (2006). Regimes of youth transitions: Choice, flexibility and security in young people's experiences across different European contexts. Young, 14(2), 119-139.

Walther, A. (2017). Support across life course regimes. A comparative model of social work as construction of social problems, needs, and rights. Journal of Social Work, 17(3), 277-301.

Walther, A., \& Stauber, B. (2006). De-standardised pathways to adulthood: European perspectives on informal learning in informal networks. Papers, 79, 242-262.

\section{About the Authors}
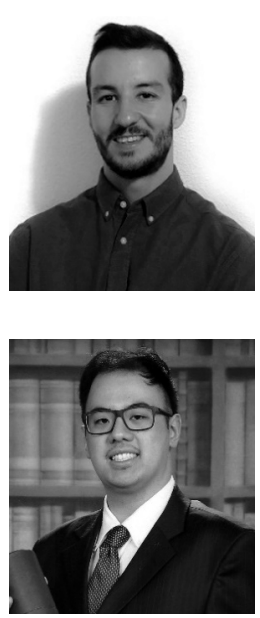

Domingo Barroso-Hurtado holds a bachelor's in Social Educational Work and a master's degree in Criminality and Social Intervention with Minors. He is a Research Fellow of the Spanish Ministry of Education (FPU programme) at the Department of Pedagogy at the University of Granada. At the moment, he is finishing his doctoral dissertation, which is related to the content of the European research project YOUNG_ADULLLT. His main research interests are Vocational Education and Training and life course studies.

Ralph Chan is a Junior Researcher at the University of Vienna. He holds a BA and a MA degree in Sociology from the University of Vienna. His research interests are sociology of education, sociology of youth, urban studies and social policy. His research areas are closely connected to the topic of the paper as he has researched on the Austrian education and training system and has experience in interviews with youths and young adults. Currently, he is writing his $\mathrm{PhD}$ thesis on the decision process of Austrian youths in school-to-school or school-to-work transition. 